Dimitris Georgopoulos

\title{
Ineffective efforts during mechanical ventilation: the brain wants, the machine declines
}

Received: 27 December 2011

Accepted: 30 December 2011

Published online: 2 February 2012

(C) Copyright jointly held by Springer and ESICM 2012

This editorial refers to the article available at: doi:10.1007/s00134-012-2493-4.

\section{Georgopoulos (匹)}

Department of Intensive Care Medicine,

University Hospital of Heraklion, Medical School,

University of Crete, Heraklion, Crete, Greece

e-mail: georgop@med.uoc.gr

Fax: +30-281-0392409

Asynchrony between patient and ventilator occurs when there is a mismatch between the patient and ventilator inspiratory and expiratory times [1]. This mismatch may be due to inspiratory and expiratory delays, which are almost inevitable with most ventilatory modes, and/or to major asynchronies such as autotriggering (the ventilator is triggered in the absence of patient effort), multiple triggering (one inspiratory effort triggers the ventilator more than once), and ineffective triggering (the patient's inspiratory effort fails to trigger the ventilator) [1, 2]. Ineffective triggering (or ineffective efforts, IE) is a commonly encountered major asynchrony $[2,3]$ and may occur during either the inspiratory or the expiratory ventilator phase [4]. The incidence of IE depends on several factors such as the population studied, the ventilator settings, the sedation depth, and the sleep/awake state [2, 3, 5-8]. de Wit et al. [9] studied a population of unselected critically ill patients within the first $24 \mathrm{~h}$ of mechanical ventilation and found that $27 \%$ of patients exhibited IE in more than $10 \%$ of their inspiratory efforts. In obstructive lung disease IE have been observed in up to $80 \%$ of patients $[7,8]$.
Provided that triggering sensitivity of the ventilator is correctly set, IE imply the existence of dynamic hyperinflation [1]. When dynamic hyperinflation is present, inspiratory effort begins at lung volumes above the passive functional residual capacity as determined by external positive end-expiratory pressure (PEEPe). Consequently, elastic recoil pressure at the beginning of inspiration is higher than PEEPe. This difference in elastic recoil pressure, referred to as intrinsic PEEP (PEEPi), represents an elastic threshold load for the patient. With flow or pressure triggering systems, the patient must first generate an inspiratory muscle pressure equivalent to PEEPi in order to be able to decrease alveolar pressure below PEEPe and trigger the ventilator. If PEEPi is high and/or inspiratory effort is weak the inspiratory muscle may not counterbalance this load and IE will ensue [1, 4]. Any factor that promotes dynamic hyperinflation (i.e., obstructive lung disease, tachypnea, high tidal volume due to high level of assist, delayed cycling off) places the patient at risk of IE $[1,2,5]$. The risk is further augmented by any other cause that decreases the inspiratory muscle pressure (i.e., sedation, sleep, respiratory or metabolic alkalosis, polyneuromyopathy) $[1,3]$.

Although IE have been observed with all modes of assisted ventilation, the likelihood of this asynchrony is reduced with proportional assist ventilation (PAV) and, particularly, with neurally adjusted ventilatory assist (NAVA) [10-12]. With these modes mechanical inflation time is terminated close to the end of neural inspiration, and tidal volume in most cases remains relatively small independent of the assist level. In addition, NAVA does not depend on the counterbalance of PEEPi for triggering, because diaphragmatic EMG may be used as the triggering signal. This may also contribute to IE reduction. Similarly, the number of IE may be decreased by other methods that improve the triggering sensitivity [13]. 
Should IE be identified and, if possible, corrected? The answer is not straightforward because there are no studies that specifically address this issue. However, there is reason to believe that IE may have serious consequences for the mechanically ventilated patients. Unrecognized IE could affect the decision-making process because in patients with this asynchrony the ventilator rate underestimates, sometimes substantially, the true breathing frequency $[4,11,14]$. In these patients any change in ventilator settings that causes a decrease in dynamic hyperinflation will improve the ability of the patient to trigger the ventilator and as result respiratory rate will increase. The increase in respiratory rate may be erroneously viewed as a sign of respiratory distress, causing unnecessary delays in the weaning process. Likewise, computerized weaning protocols in which the change in ventilator settings is based on ventilator rate, without taking into consideration the phenomenon of IE, [15] may also lead to weaning delays in this group of patients.

In theory, IE during expiration may cause inspiratory muscle damage. This type of asynchrony implies that inspiratory muscles are activated to contract when they would normally be lengthening as lung volume decreases (lengthening contraction). It is well known that lengthening contractions of skeletal muscles (including the diaphragm) cause ultrastructural damage to muscle fibers, resulting in acute, sustained, and profound impairment of force generation [16, 17]. No study of mechanically ventilated patients has addressed this possibility so far.

It has been shown that critically ill patients with significant numbers of IE have increased duration of mechanical ventilation, shorter ventilator-free survival, increased length of stay, and lower likelihood of home discharge [9]. Other studies have also suggested that major asynchrony, including IE, is associated with prolonged mechanical ventilation, unsuccessful weaning, sleep fragmentation, and discomfort [2, 12, 18-20]. Finally, during noninvasive mechanical ventilation IE are related to nocturnal desaturation and reduced REM sleep $[6,21]$. Nevertheless, none of these studies were designed to prove the cause-effect relationship of IE and this important issue should be further explored.

How can we identify IE? The gold standard is either to insert an esophageal balloon to measure esophageal pressure or to record diaphragmatic EMG (EAdi), preferably using the nasogastric route (i.e., NAVA technology). However, these techniques are not suitable for everyday practice, requiring some expertise and special equipment, and are relatively invasive. Alternatively, bedside evaluation of flow-time and pressure-time waveforms may be used to identify IE as well as other types of asynchrony [4]. This technique, nevertheless, also requires expertise. In addition, it necessitates the presence of the caregiver for the identification of the asynchrony. Therefore, automatic detection and recording of IE using noninvasive methods that do not interfere with patients' management and preferably are not affected by noise (i.e., secretions, body movements) are welcome. In recent years several methods of automatic detection of IE during invasive or noninvasive mechanical ventilation have been published [14, 22-24]. In this issue of Intensive Care Medicine Blanch et al. [25] present one such method validated in a small number of intubated patients. They developed an algorithm that excludes the first $100 \mathrm{~ms}$ of expiration and analyzes the remaining expiratory flowtime waveform. IE were detected as a specific deviation of flow-time curve from the curve that satisfies certain criteria. In addition the algorithm can detect IE even in the presence of secretion, an important feature for long-term application. The accuracy of IE detection was similar to that of expert intensivist as well as of EAdi signal, recorded using the NAVA technology. Obviously, this method does not recognize IE during either inspiration or early expiration and therefore may underestimate the true incidence of IE. In addition the method has not been validated for noninvasive ventilation, where air leaks are common. It also needs to be validated for a larger population of critically ill patients with a variety of disorders. Despite these limitations, the fact that it can be applied for a long time is an advantage because this asynchrony event is time dependent.

The next step is further tuning the automated methods of IE detection (preferably including all types of patientventilator asynchrony) in order to allow their use as a reliable tool to properly study the relationship between asynchrony and outcome, an issue which is largely unexplored. Apart of asynchrony identification, these methods may serve as feedback systems either to guide the caregiver or be used in a closed system technology in order to improve the patient-ventilator synchrony.

\section{References}

1. Kondili E, Prinianakis G, Georgopoulos D (2003) Patient-ventilator interaction. Br J Anaesth 91:106-119

2. Thille AW, Rodriguez P, Cabello B Lellouche F, Brochard L (2006) Patientventilator asynchrony during assisted mechanical ventilation. Intensive Care Med 32:1515-1522
3. de Wit M, Pedram S, Best AM, Epstein SK (2009) Observational study of patient-ventilator asynchrony and relationship to sedation level. J Crit Care 24:74-80
4. Georgopoulos D, Prinianakis G, Kondili E (2006) Bedside waveforms interpretation as a tool to identify patient-ventilator asynchronies. Intensive Care Med 32:34-47 
5. Thille AW, Cabello B, Galia F, Lyazidi A, Brochard L (2008) Reduction of patient-ventilator asynchrony by reducing tidal volume during pressuresupport ventilation. Intensive Care Med 34:1477-1486

6. Fanfulla F, Delmastro M, Berardinelli A, Lupo ND, Nava S (2005) Effects of different ventilator settings on sleep and inspiratory effort in patients with neuromuscular disease. Am J Respir Crit Care Med 172:619-624

7. Nava S, Bruschi C, Fracchia C, Braschi A, Rubini F (1997) Patient-ventilator interaction and inspiratory effort during pressure support ventilation in patients with different pathologies. Eur Respir J 10:177-183

8. Purro A, Appendini L, De Gaetano A, Gudjonsdottir M, Donner CF, Rossi A (2000) Physiologic determinants of ventilator dependence in long-term mechanically ventilated patients. Am J Respir Crit Care Med 161:1115-1123

9. de Wit M, Miller KB, Green DA, Ostman HE, Gennings C, Epstein SK (2009) Ineffective triggering predicts increased duration of mechanical ventilation. Crit Care Med 37:2740-2745

10. Terzi N, Pelieu I, Guittet L, Ramakers M, Seguin A, Daubin C, Charbonneau P, du Cheyron D, Lofaso F (2010) Neurally adjusted ventilatory assist in patients recovering spontaneous breathing after acute respiratory distress syndrome: physiological evaluation. Crit Care Med 38:1830-1837

11. Giannouli E, Webster K, Roberts D, Younes M (1999) Response of ventilator-dependent patients to different levels of pressure support and proportional assist. Am J Respir Crit Care Med 159:1716-1725
12. Xirouchaki N, Kondili E, Vaporidi K, Xirouchakis G, Klimathianaki M, Gavriilidis G, Alexandopoulou E, Plataki M, Alexopoulou C, Georgopoulos D (2008) Proportional assist ventilation with load-adjustable gain factors in critically ill patients: comparison with pressure support. Intensive Care Med 34:2026-2034

13. Prinianakis G, Kondili E, Georgopoulos D (2003) Effects of the flow waveform method of triggering and cycling on patient-ventilator interaction during pressure support. Intensive Care Med 29:1950-1959

14. Younes M, Brochard L, Grasso S, Kun J, Mancebo J, Ranieri M, Richard JC, Younes H (2007) A method for monitoring and improving patient: ventilator interaction. Intensive Care Med 33:1337-1346

15. Lellouche F, Mancebo J, Jolliet P, Roeseler J, Schortgen F, Dojat M, Cabello B, Bouadma L, Rodriguez P, Maggiore S, Reynaert M, Mersmann S, Brochard L (2006) A multicenter randomized trial of computer-driven protocolized weaning from mechanical ventilation. Am J Respir Crit Care Med 174:894-900

16. Watchko JF, Johnson BD, Gosselin LE, Prakash YS, Sieck GC (1994) Agerelated differences in diaphragm muscle injury after lengthening activations. J Appl Physiol 77:2125-2133

17. Gosselin LE, Burton H (2002) Impact of initial muscle length on force deficit following lengthening contractions in mammalian skeletal muscle. Muscle Nerve 25:822-827

18. Bosma K, Ferreyra G, Ambrogio C, Pasero D, Mirabella L, Braghiroli A, Appendini L, Mascia L, Ranieri VM (2007) Patient-ventilator interaction and sleep in mechanically ventilated patients: pressure support versus proportional assist ventilation. Crit Care Med 35:1048-1054
19. Chao DC, Scheinhorn DJ, StearnHassenpflug M (1997) Patientventilator trigger asynchrony in prolonged mechanical ventilation. Chest 112:1592-1599

20. Vignaux L, Vargas F, Roeseler J, Tassaux D, Thille AW, Kossowsky MP, Brochard L, Jolliet P (2009) Patientventilator asynchrony during noninvasive ventilation for acute respiratory failure: a multicenter study. Intensive Care Med 35:840-846

21. Fanfulla F, Taurino AE, Lupo ND, Trentin R, D'Ambrosio C, Nava S (2007) Effect of sleep on patient/ ventilator asynchrony in patients undergoing chronic non-invasive mechanical ventilation. Respir Med 101:1702-1707

22. Cuvelier A, Achour L Rabarimanantsoa H, Letellier C, Muir JF, Fauroux B (2010) A noninvasive method to identify ineffective triggering in patients with noninvasive pressure support ventilation. Respiration 80:198-206

23. Mulqueeny Q, Ceriana $\mathrm{P}$, Carlucci A, Fanfulla F, Delmastro M, Nava S (2007) Automatic detection of ineffective triggering and double triggering during mechanical ventilation. Intensive Care Med 33:2014-2018

24. Chen CW, Lin WC, Hsu CH, Cheng KS, Lo CS (2008) Detecting ineffective triggering in the expiratory phase in mechanically ventilated patients based on airway flow and pressure deflection: feasibility of using a computer algorithm. Crit Care Med 36:455-461

25. Blanch L, Sales B, Montanya J, Lucangel U, Garcia-Esquirol O, Villagra A, Chacon E, Estruga A, Borelli M, Burgueñ MJ, Joan C, Oliva RF, Villar J, Kacmarek R, Murias G (2012) Validation of the Better Care ${ }^{\circledR}$ system to detect ineffective efforts during expiration in mechanically ventilated patients: a pilot study. Intensive Care Med. doi: 10.1007/s00134-012-2493-4 